of dealing with the problem of anaesthetic contamination. This venting system has been in use for over six monthes in two operating theatres.

Although the whole problem of operating theatre pollution seems to merit further investigation, it is clear that until such time as the agent causing the possible deleterious effect on operating theatre personnel is identified all the anaesthetic gases and vapours should be vented from the operating room.-I am, etc. Burnley General Hospital,
Burnley, Lancs

S. MEHTA

1 Nikki P., Pfäffi, P., and Ahlman, K., Lancet, $1972,2,490$

Askrog, V., and Petersen, R., Nordisk Medicin, 1970, 83, 501 .

Lassen, H. C. A., Henriksen, E., Neukirch, F., and Kristensen, H. S., Lancet, 1956, 1, 527 . Bckenhoff, J. Eide, E., Anesthesiology, 1968, 29,' 565 . 5 Johnson, B. B., Lancet 1972, 2, 824

Kieler, J. 1957, Acta Pharmacologica et Toxicologica, 1957, 13, 301.

Bruemmer, J. H.; Brunetti, B. B., and Shreiner,
H. R., fournal of Cellular and Comparative Physiology, 1967, 69, 285 .

Fink, B. R., and Kenny, G. B., Anesthesiology, $1968,29,505$.

SIR,-In recent years evidence has been accumulating that doctors tend to reach hasty conclusions when confronted by a problem. In your leading article (24 March, p. 693) you refer to a paper by E. N. Cohen and his colleagues ${ }^{1}$ showing that spontaneous abortion in nurses working in operating rooms was significantly higher than in those on general duties. This reference was associated with work by Whitcher et al., ${ }^{2}$ who measured halothane concentrations in two large operating rooms.

Any contamination of the environment should be avoided, but it is dangerous to assume that the solution to a problem has been found before it has been fully investigated. Obviously we want to reduce the spontaneous abortion rate among nurses in operating theatres, but there appears to be no scientific evidence that it is the theatre halothane concentration which is responsible. It would be sad if we filled our operating theatres with cumbersome devices in order to minimize a risk which has not been proved. It may well be that the mental srtain of working in a theatre with people like anaesthetists and surgeons is more than enough to increase the spontaneous abortion rate. Many other possible causes could be adduced.-I am, etc.

\section{St. Thomas's Hospital,}

T. H. S. BURNS

1 Cohen, E. N., Belville, J. W., and Brown, B. W., 2 Anesthesiology, 1971, 35, 343. J. R., Anesthesiology, 1971, 35, 348.

\section{Coeliac Disease and Schizophrenia}

SIR,-The paper by Dr. M. Mylotte and others (24 March, p. 703) showing a greatly increased incidence of coeliac disease in the West of Ireland in an area where the firstadmission expectancy for schizophrenia is also greatly raised ${ }^{1}$ resurrects the possibility of a relationship between these two disorders which has been documented by Dohan. ${ }^{2}$

The evidence for such a relationship derives from four sources: (1)-The apparently increased incidence of schizophrenia in those suffering from coeliac disease. (2)-Certain munological and biochemical associations between schizophrenia and coeliac disease. ${ }^{3}$ (3)-A close association between national morbid risk for schizophrenia and national consumption of wheat and other cereals. ${ }^{4}$ (4) -The alleged clinical improvement of schizophrenics fed a cereal-free diet. ${ }^{5}$

The crucial factor in these observations is the validity of the application of the diagnosis "schizophrenia." Most of the clinical descriptions of the psychiatric conditions of coeliac children regarded as schizophrenic would not support this diagnosis but rather that of a non-specific reaction to the symptoms of coeliac disease. This matter has already been alluded to by Challacombe. ${ }^{6}$

Nevertheless, it would seem that a good case can be made for looking at the relatives of coeliac children in the West of Ireland using standardized diagnostic criteria to see whether there is a raised incidence of schizophrenia among them by comparison with a control group of relatives of non-coeliac children in a community where the incidence of schizophrenia appears to be generally high.-I am, etc.,

DERMOT WALSH

Medico-social Research Board,

Dublin

Walsh, D., British foumal of Psychiatry, 1972,

121, 233.
Dohan, F. C., in Schirophrenia. Current Concepts
and Research, ed. S. Sankar, New York, P.J.D. and Research, ed. S. Sankar, New York, P.J.D. ublications, 1969.

Lancaster-Smith, M., and Strickland, I., Lancet, 1970, 2, 1090 .

1966, F., Acta Psychiatrica Scandinavica, Dohan, F. C., Grasberger, J. C., Lowell, F. M., Johnston, H. T., Jun., and Ärbegast, A: W. Chalnicombe, D. N., Lancet, 1971, 1, 89.

\section{Treatment of Depression in General} Practice

SiR,-In his article on the treatment of depression in general practice ( 7 April, p. 18) Dr. D. A. W. Johnson omits to say definitely whether the patients studied recovered from their depression. One assumes that they did from such statements as "the patients made the ratings after their recovery from depression" and "the cases of depression seen in these general practices seem ... to have been mostly a self-limiting illness." Surely it is not possible to judge the effectiveness of treatment without reference to whether or not the patient gets better from his illness.

Dr. Johnson states that the study indicates that "patients with depressive illness do not receive the best possible treatment" in general practice. It seems to me that this conclusion can be reached only if it is shown that patients receiving treatment in general practice do not get better, or that they get better more quickly and more permanently with some other treatment. This has not been shown. After all, these patients received treatment, they had contact with their doctor, and they were given drugs. If they got better, and there is no evidence in this article to suggest that they did not, then no more is required. The fact that they did not receive the kind and amount of drugs which the author would have used is beside the point. Indeed, if they did get better without adequate drug treatment, this suggests that perhaps the doctor-patient contact was the therapeutic agent.-I am, etc.,

Waterlooville,

K. B. THOMAS
SIR,-I wish to comment on the study of depressed patients in general practice reported by Dr. D. A. W. Johnson (7 April, p. 18). Many important facts are not given, the outcome of the illnesses is left vague, and few useful conclusions can be drawn.

The number of patients in the study was small and agreement on diagnosis between the G.P.s and the psychiatrist was good. The psychiatrist regarded the treatment as poor, but apparently most of the patients were better within four months of first attending their G.P. Dr. Johnson concludes that patients with depressive illness do not receive the best treatment in general practice. Such a conclusion is not self-evident and may cause one to wonder just what he set out to prove.

The five general practices were held in high esteem; they also represented a crosssection of G.P.s and practices. Perhaps Dr. Johnson is trying to be polite, but he comes over as confused. A total of 112 patients were referred for his study, and he saw 97 of them. We have his opinion that two were not depressed, and we hear no more of them. Fifteen were given a primary diagnosis of "personality disorder"-perhaps more of a social judgement or expression of doctorpatient incompatibility than a diagnosis and one which certainly does not exclude the presence of depression. Again we hear no more of them. Eventually more than a third of the patients were excluded and 73 were studied, a number which scarcely permits the use of percentages in subsequent analyses. With a panoply of professional skills and diagnostic inventories the psychiatrist agreed with the G.P.s about the condition of these patients, 30 of whom were in the early stages of their illness.

None of the patients received psychotherapy, none received help from social agencies, very few took an "adequate" dosage of antidepressant tablets, and only 11 said they had received personal help or support from their G.P. This sounds so appalling that one wonders what happened to them. Dr. Johnson is remarkably vague about this. Half had been unable to follow their usual life, but they are not identified against the variables considered, nor do we learn if they did resume normal life. Two took overdoses, but we are not told if they differed from the rest in other respects. It is merely stated that the depressive episodes seem to have been mostly self-limiting within a fourmonth period.

Most of the patients were apparently responding to stresses of various kinds (Dr. Johnson is lucky to be able to categorize these so precisely) and recovery was associated with relief from the stress. Since recovery was pretty rapid and the stresses relieved without medical or social help, we may suppose that the patients had illnesses of a kind not usually referred to psychiatrists and therefore perhaps difficult for Dr. Johnson to evaluate.

The patients were nearly all very satisfied with their G.P., though few reported any help from their relationship with him in this illness. This extraordinary juxtaposition of statements might have caused Dr. Johnson more thought than he records. Were they really so satisfied? Did they really receive so little help? Can Dr. Johnson think of any psychological mechanisms that might underlie these statements of patients recently re- 